\title{
Echocardiographic Assessment of Cardiac Structural and Functional Indices in Broiler Chickens Treated with Silver Nanoparticles
}

\author{
Hamid Raieszadeh, ${ }^{1}$ Vahid Noaman, ${ }^{2}$ and Mehrdad Yadegari ${ }^{3}$ \\ ${ }^{1}$ Postgraduate Veterinary Medicine, Shahrekord Branch, Islamic Azad University, Shahrekord, Iran \\ ${ }^{2}$ Department of Veterinary Research, Isfahan Research Center for Agriculture and Natural Resources, P.O. Box 81785-199, Isfahan, Iran \\ ${ }^{3}$ Department of Radiology, Faculty of Veterinary Medicine, Shahrekord Branch, Islamic Azad University, Shahrekord, Iran \\ Correspondence should be addressed to Vahid Noaman; vnoaman@gmail.com
}

Received 4 August 2013; Accepted 11 September 2013

Academic Editors: D. Endoh and J. Klein

Copyright (C) 2013 Hamid Raieszadeh et al. This is an open access article distributed under the Creative Commons Attribution License, which permits unrestricted use, distribution, and reproduction in any medium, provided the original work is properly cited.

\begin{abstract}
270 Ross broiler chickens of twenty days old were housed in 18-floor pens in a completely randomized design with six treatment groups and three replicate groups and fifteen chicks per each pen. The treatment groups (1-6) consisted of 0, 10, 20, 30, 50, and $70 \mathrm{ppm}$ of nanocide in drinking water, respectively. At 26 days of age, 3 chickens were selected randomly for echocardiography using a $7.5 \mathrm{MHz}$ linear probe, and the left ventricular internal diameter at the end of diastole (LVIDd), left ventricular internal diameter at the end of systole (LVIDs), left ventricular fractional shortening (LVFS), ejection fraction (EF), stroke volume (SV), interventricular septum thickness at the end of systole (IVSTs), and interventricular septum thickness at the end of diastole (IVSTd) were evaluated. LVIDd and LVIDs in group six were of higher rate than other groups and showed statistically significant differences with groups two, three, and four $(P<0.05)$. LVFS, percentage of EF, and IVSTd were minimum in group six and had significant difference with other groups $(P<0.05)$. The results of this study showed that prescription of high dosage of nanocide leads to cardiovascular problems with decrease in myocardial contractility and increase in the internal diameter of left ventricle.
\end{abstract}

\section{Introduction}

Silver is a noble metal that has been known since ancient time to control microbial proliferation even against antibiotic-resistant bacteria [1-3]. After clarifying the properties of silver in burn wound healing and its antihemorrhagic and antiinflammatory effect, silver was used more than previously [48]. Recent studies on use of silver in nanosize as an alternative to antibiotics and its preprobiotic properties with increasing immunity have led to use of this nanoparticle largely, especially in veterinary and dependent sciences [9-12].

Not only widespread use of nanosilver in low levels of silver ions promotes rapid development of bacterial resistance but also use of nanosilver in high levels of silver ions causes toxicity in human and animals [13]. In vitro studies have found that nanosilver was toxic to mammalian liver cells, stem cells, and even brain cells [14-16].
Early examples in agriculture include the use of nanosilver as a "nanobiotic" in poultry production [17], and in recent years, the quantities of nanosilver consumed in broiler chicken farms of Iran as nano-biotic have increased considerably. Despite continued and the widespread use of nanosilver in poultry farms, to our knowledge, there is very little information about the effects of nanosilver on the vital organs, especially cardiac structure and cardiac function of chickens. Various aspects of echocardiography (such as onedimensional method, two-dimensional method and doppler method) are used for definiting anatomy of heart, evaluating cardiac structure and function, and measuring the heart cavities and coronary blood flow patterns in different species of human, horse, dog, and cat $[18,19]$. As regarded ultrasound is valuable, and noninvasive diagnostic applications in veterinary medicine and in many cases can be replaced by other 
imaging methods to assess cardiac structure and function [20-22]; this method was used in this study. Therefore, the present study was conducted to evaluate the effect of different doses of nanosilver on cardiac structure and function indicators by echocardiographic technique.

\section{Materials and Methods}

The study was carried out on 270 Ross broiler chickens twenty days old with about the same weight. The Chicks were of housed in 18-floor pens in a completely randomized design with six treatment and three replicate groups and fifteen chicks per each pen. The birds received water and food ad libitum, in feeders and linear troughs. The treatment groups consisted of different concentrations of nanocide in drinking water (group 1: $0 \mathrm{ppm}$, group 2:10 ppm, group 3:20 ppm, group 4: $30 \mathrm{ppm}$, group 5: $50 \mathrm{ppm}$, and group 6: $70 \mathrm{ppm}$ ). The active ingredient of this combination is colloidal silver with nanoside brand which is made in Behban chemical Co. At 26 days of age from each pen (repeat), 3 chickens were selected randomly and were transferred to the examination hall. After stress reduction and calming the bird, echocardiography was performed from each chick. The sternal feathers (echocardiography probe placement) slowly and without bleeding were short, and chickens for echocardiographic studies were transferred to hospital ultrasound room. With appropriate adjustments in the light, chicks were in the lowest stress. Chicken echocardiograms have been taken using a $7.5 \mathrm{MHz}$ linear probe. Chickens were in dorsal recumbency. The most common approach is ventromedial, just caudal to the sternum, viewing the heart through the liver. Patients may be held in partial upright dorsal recumbency or completely vertical position for this approach [23]. In this study, given that the left chambers of heart are examined, All the best images are obtained when the bird is in the dorsal recumbency and probe is placed in the right parasternal just in front of the stifle joint (Figure 1). In this study, echocardiography was performed in two methods B-mode and Mmode. For overall and large assessment of the heart twodimensional echocardiographic method or B-mode and to accurately measure cavity and distance between them, the Mmode echocardiography was used. At first, heart was investigated by the presence or absence of pericardial effusion. Distance between two troughs and distance between two peaks was used for measurement of left ventricular internal diameter in the end of diastole (LVIDd) and left ventricular internal diameter in the end of systole (LVIDs), respectively (Figure 2). Interventricular septum thickness in the end of diastole (IVSTd) and inter ventricular septum thickness in the end of systole (IVSTs) were measured for each sample separately. Fractional shortening (FS) or "end-diastolic diameter minus end-systolic diameter divided by end-diastolic diameter" was calculated for left ventricle (LVFS) [24, 25]. Stroke volume (SV) or "left ventricular diastolic volume (LVVd) minus left ventricular systolic volume (LVVs)" and ejection fraction (EF) or "stroke volume divided by LVVd" were evaluated $[26,27]$. The data were analyzed by the GLM procedure of SAS software. Mean values, standard deviations, and statistical differences were calculated among treatment

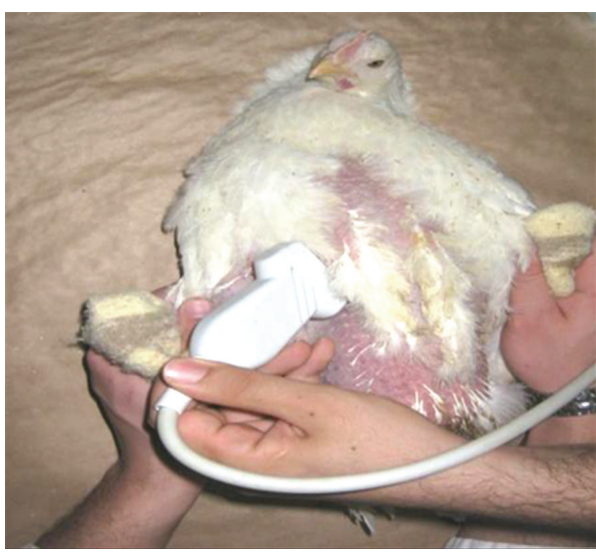

FIGURE 1: Position of transducer which is used for imaging echocardiography in chicken.

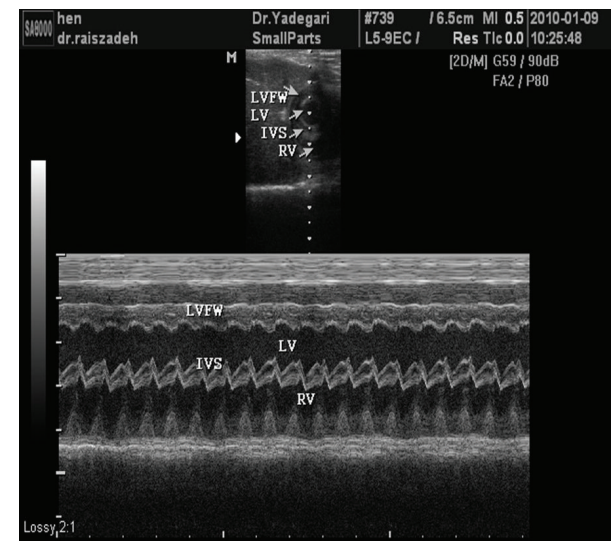

Figure 2: B-mode and M-mode echocardiography. Left ventricle $(\mathrm{LV})$, right ventricle (RV), left ventricular free wall (LVFW), and wall between the two ventricles (IVS).

groups. Duncan's multiple range tests were used to determine differences among the means. Statistically significant level of difference was considered at $P<0.05$.

\section{Results}

With clear M- and B-mode images, all data were collected. LVIDd and LVIDs in group six were of higher rate than other groups and showed statistically significant differences with groups two, three, and four $(P<0.05)$. LVFS was minimum in group six and had significant difference with groups one, two, and three $(P<0.05)$. Percentage of EF was minimum in group six and had significant difference with groups two and three $(P<0.05)$. IVSTd was minimum in group six and had significant difference with groups one, four, and five $(P<0.05)$. No significant difference was observed in IVSTs in different groups. Stroke volume in groups five and six was slightly higher than other groups, but those differences were not statistically significant (Table 1). In Bmode, echocardiographic images clearly observed pericardial effusion in groups five and six (Figure 3). 
TABLE 1: Comparison of echocardiographic indices (Means \pm Standard deviation) among different chicken groups treated with nanoparticles.

\begin{tabular}{|c|c|c|c|c|c|c|c|}
\hline \multirow{2}{*}{ Treatment groups } & \multicolumn{7}{|c|}{ Cardiac parameters $^{1}$} \\
\hline & LVIDd & LVIDs & LVFS & $\mathrm{EF}$ & IVSTd & IVSTs & SV \\
\hline $1(0 \mathrm{ppm})$ & $1.08 \pm 0.03^{\mathrm{ab}}$ & $0.56 \pm 0.02^{\mathrm{ab}}$ & $47.82 \pm 0.92^{\mathrm{a}}$ & $83.77 \pm 0.98^{\mathrm{ab}}$ & $0.34 \pm 0.02^{\mathrm{a}}$ & $0.42 \pm 0.02$ & $2.19 \pm 0.11$ \\
\hline $2(10 \mathrm{ppm})$ & $1.04 \pm 0.02^{\mathrm{b}}$ & $0.51 \pm 0.02^{\mathrm{b}}$ & $51.29 \pm 1.30^{\mathrm{a}}$ & $85.36 \pm 1.62^{\mathrm{a}}$ & $0.32 \pm 0.01^{\mathrm{ab}}$ & $0.43 \pm 0.03$ & $2.02 \pm 0.15$ \\
\hline $3(20 \mathrm{ppm})$ & $1.02 \pm 0.01^{\mathrm{b}}$ & $0.50 \pm 0.03^{\mathrm{b}}$ & $50.77 \pm 3.57^{\mathrm{a}}$ & $85.48 \pm 2.41^{\mathrm{a}}$ & $0.32 \pm 0.01^{\mathrm{ab}}$ & $0.43 \pm 0.01$ & $2.09 \pm 0.30$ \\
\hline $4(30 \mathrm{ppm})$ & $1.01 \pm 0.02^{\mathrm{b}}$ & $0.53 \pm 0.01^{\mathrm{b}}$ & $47.70 \pm 0.52^{\mathrm{ab}}$ & $83.05 \pm 0.54^{\mathrm{ab}}$ & $0.36 \pm 0.01^{\mathrm{a}}$ & $0.40 \pm 0.03$ & $1.88 \pm 0.09$ \\
\hline $5(50 \mathrm{ppm})$ & $1.03 \pm 0.02^{\mathrm{ab}}$ & $0.55 \pm 0.06^{\mathrm{ab}}$ & $46.42 \pm 5.75^{\mathrm{ab}}$ & $81.61 \pm 5.15^{\mathrm{ab}}$ & $0.33 \pm 0.03^{\mathrm{a}}$ & $0.36 \pm 0.04$ & $1.80 \pm 0.16$ \\
\hline $6(70 \mathrm{ppm})$ & $1.09 \pm 0.06^{\mathrm{a}}$ & $0.62 \pm 0.05^{\mathrm{a}}$ & $42.32 \pm 1.82^{\mathrm{b}}$ & $79.40 \pm 3.95^{\mathrm{b}}$ & $0.29 \pm 0.01^{\mathrm{b}}$ & $0.38 \pm 0.01$ & $1.84 \pm 0.07$ \\
\hline
\end{tabular}

${ }^{\mathrm{a}-\mathrm{b}}$ Different superscript letters in each column indicate significant difference between groups $(P<0.05)$.

Data are reported as mean $\pm \mathrm{SD}$.

${ }^{1}$ LVIDd: left ventricular internal diameter in the end of diastole; LVIDs: left ventricular internal diameter in the end of systole; LVFS: left ventricular fractional shortening; EF: ejection fraction; IVSTd: interventricular septum thickness in the end of diastole; IVSTs: inter ventricular septum thickness in the end of systole; SV: stroke volume.

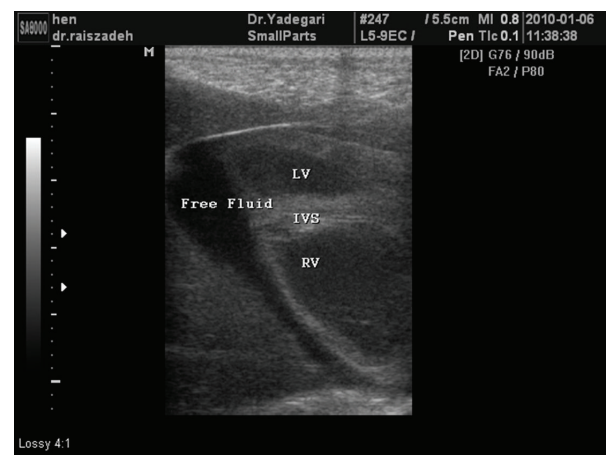

FIGURE 3: Pericardial effusion in group six.

\section{Discussion}

Antibacterial and antiseptic effects of silver ion in preventing infection with coli forms, staphylococcus, and streptococcus have been proven in previous studies [26-29]. Silver nanoparticles can destroy many kinds of bacteria, viruses, and fungi, and it is recommended that it can be used in the treatment of certain viral diseases in animals like Influenza and Newcastle [30]. However, extended and excessive exposure to the silver nanoparticles, like many other drugs, has side effects and pathologic effect on living tissues. Sung et al. and other researchers indicated that the use of nanoscale silver in the drinking water and inhalation has toxic effects (hyperplasia, fibrosis, and vacuolation) on organs such as the liver and lungs $[31,32]$. Heart as a vital organ of the birds is sensitive to different medications and shows different reactions [33]. Despite the widespread use of nanosilver products in poultry farms, relatively few studies have been undertaken to determine the biological effects of nanosilver exposure [34]. Because of the lack of information on the effects of silver nanoparticles on the heart, in this study, the effects of different doses of nanosilver on cardiac structure and function were evaluated.

Absorbed nanosilvers bind to plasma proteins and can enter the cells. They are distributed in organs such as liver, kidney, heart, lymph nodes, brain, lung, stomach, and testicles [35]. The rate of silver retention is not the same in different organs; this situation may be related to activity, blood flow rate in the organs [36]. Recently, it was reported that nanoparticles and nanomaterials generate free radicals and oxidative stress [16]. The results of research showed that silver nanoparticles can damage different organs and tissues [15]. Cytotoxicity of silver nanoparticles to the mitochondrial activity increased with the increase in the concentration of silver nanoparticles, and silver nano-particles are the most toxic with drastic reduction of mitochondrial function, increased membrane leakage, necrosis, and induction of apoptosis [34]. Cardiac necroses and decrease of blood glutathione per oxidase have been reported in silver treated swine [37]. LVFS is the most important indicator of heart function, and in the present study, in group six (70 ppm), decreased LVFS was observed. Indeed, increasing nanosilver consumption causes heart and lung damage [34]. Reduced lung capacity and myocardial lesions cause pulmonary hypertension, and ascites also contribute to the development of compensatory right ventricular hypertrophy [38], dilated myopathy, and decreased LVFS. In dilated myopathy, the heart size is increased without increasing the thickness of the heart muscle, even the walls are thinner to increase the size of chambers [33]. Following this, the increase will occur in LVIDd and LVIDs.

According to formula FS\% = (LVIDd - LVIDs $) \times$ 100/LVIDd and the direct connection between LVIDd and LVFS, increased percentage of LVFS in groups that developed this complication is probably due to the above changes. Deng et al. in a study on heart parameters of chickens with ascites syndrome and normal chickens showed an increase in LVDs and a decrease in FS of chickens with ascites syndrome [39]. In another study, cardiac echocardiography on chickens with pulmonary hypertension syndrome (PHS) showed that FS in right and left ventricles was decreased and RVID in the end of systole and diastole was increased [40].

Stroke volume is the volume of blood ejected per heart beat and influenced by preload, afterload, and contractility [24]. Reduction of inter ventricular thicknesses and heart muscle myopathy in groups with high dose of nano silver 
results in myocardial contractility reduction which consequently led to the stroke volume reduction.

According to ejection fraction formula $\mathrm{EF} \%=(\mathrm{SV} \times$ $100 /$ LVVd) with decreasing stroke volume, the percentage of ejection fraction in groups with high doses of nanosilver especially group six is reduced.

Pericardial effusion is an abnormal accumulation of fluid in the pericardial cavity, that is, a pathological condition [41]. In this study, pericardial effusion in the group with high dose of nanosilver probably was the result of silver toxicity and consequently myocardial and liver damage that leads to blood reject from the heart, passive congestion, and consequently hydropericardium and ascites.

\section{Conclusion}

Recent study showed negative effects of high dose silver nano particle on cardiac structure and function in chicken. In addition,the survey results showed that the most important changes in cardiac parameters can be due to decreased cardiac contractility that probably has occurred due to toxicity with high dose of nano silver.

\section{Acknowledgment}

This work was supported by Veterinary Faculty of Islamic Azad University of Shahrekord. The authors declare that there is no conflict of interests.

\section{References}

[1] A. Wadhera and M. Fung, "Systemic argyria associated with ingestion of colloidal silver," Dermatology Online Journal, vol. 11, no. 1, pp. 11-12, 2005.

[2] J. R. Morones, J. L. Elechiguerra, A. Camacho et al., "The bactericidal effect of silver nanoparticles," Nanotechnology, vol. 16, no. 10, pp. 2346-2353, 2005.

[3] J. B. Wright, K. Lam, and R. E. Burrell, "Wound management in an era of increasing bacterial antibiotic resistance: a role for topical silver treatment," American Journal of Infection Control, vol. 26, no. 6, pp. 572-577, 1998.

[4] J. B. Wright, K. Lam, A. G. Buret, M. E. Olson, and R. E. Burrell, "Early healing events in a porcine model of contaminated wounds: effects of nanocrystalline silver on matrix metalloproteinases, cell apoptosis, and healing," Wound Repair and Regeneration, vol. 10, no. 3, pp. 141-151, 2002.

[5] D. A. Ross, A. J. Phipps, and J. A. Clarke, "The use of cerium nitrate-silver sulphadiazine as a topical burns dressing," British Journal of Plastic Surgery, vol. 46, no. 7, pp. 582-584, 1993.

[6] D. M. Caruso, K. N. Foster, M. H. E. Hermans, and C. Rick, "Aquacel Ag in the management of partial-thickness burns: results of a clinical trial," Journal of Burn Care and Rehabilitation, vol. 25, no. 1, pp. 89-97, 2004.

[7] K. C. Bhol and P. J. Schechter, "Topical nanocrystalline silver cream suppresses inflammatory cytokines and induces apoptosis of inflammatory cells in a murine model of allergic contact dermatitis," British Journal of Dermatology, vol. 152, no. 6, pp. 1235-1242, 2005.

[8] A. Melaiye and W. J. Youngs, "Silver and its application as an antimicrobial agent," Expert Opinion on Therapeutic Patents, vol. 15, no. 2, pp. 125-130, 2005.
[9] P. H. M. Hoet, I. Brüske-Hohlfeld, and O. V. Salata, "Nanoparticles-known and unknown health risks," Journal of Nanobiotechnology, vol. 2, article 12, 2004.

[10] S. Mandal, S. Phadtare, and M. Sastry, "Interfacing biology with nanoparticles," Current Applied Physics, vol. 5, no. 2, pp. 118-127, 2005.

[11] I. Sondi and B. Salopek-Sondi, "Silver nanoparticles as antimicrobial agent: a case study on E. coli as a model for Gramnegative bacteria," Journal of Colloid and Interface Science, vol. 275, no. 1, pp. 177-182, 2004.

[12] E. Sawosz, M. Binek, M. Grodzik et al., "Influence of hydrocolloidal silver nanoparticles on gastrointestinal microflora and morphology of enterocytes of quails," Archives of Animal Nutrition, vol. 61, no. 6, pp. 444-451, 2007.

[13] G. Crocetti and G. Miller, "Nano-silver: policy failure puts public health at risk," Friends of the Earth Australia, 2011, http://innovationsgesellschaft.ch/.

[14] S. M. Hussain, K. L. Hess, J. M. Gearhart, K. T. Geiss, and J. J. Schlager, "In vitro toxicity of nanoparticles in BRL 3A rat liver cells," Toxicology in Vitro, vol. 19, no. 7, pp. 975-983, 2005.

[15] L. Braydich-Stolle, S. Hussain, J. J. Schlager, and M.-C. Hofmann, "In vitro cytotoxicity of nanoparticles in mammalian germline stem cells," Toxicological Sciences, vol. 88, no. 2, pp. 412-419, 2005.

[16] S. M. Hussain, A. K. Javorina, A. M. Schrand, H. M. H. M. Duhart, S. F. Ali, and J. J. Schlager, "The interaction of manganese nanoparticles with PC-12 cells induces dopamine depletion," Toxicological Sciences, vol. 92, no. 2, pp. 456-463, 2006.

[17] M. Clement, "Pullet production gets nano-silver lining," 2009, http://www.wattagnet.com/Pullet_production_gets_nano-silver_lining.html.

[18] A. Kitabatake, M. Inoue, M. Asao et al., "Noninvasive evaluation of pulmonary hypertension by a pulsed Doppler technique," Circulation, vol. 68, no. 2, pp. 302-309, 1983.

[19] T. Masuyama, K. Kodama, A. Kitabatake et al., "Continuouswave Doppler echocardiographic detection of pulmonary regurgitation and its application to noninvasive estimation of pulmonary artery pressure," Circulation, vol. 74, no. 3, pp. 484492, 1986.

[20] M.-E. Krautwald-Junghanns and F. Enders, "Ultrasonography in birds," Seminars in Avian and Exotic Pet Medicine, vol. 3, pp. 140-146, 1994.

[21] R. B. Devereux, D. R. Alonso, E. M. Lutas et al., "Echocardiographic assessment of left ventricular hypertrophy: comparison to necropsy findings," American Journal of Cardiology, vol. 57, no. 6, pp. 450-458, 1986.

[22] R. B. Devereux and N. Reichek, "Echocardiographic determination of left ventricular mass in man. Anatomic validation of the method," Circulation, vol. 55, no. 4, pp. 613-618, 1977.

[23] L. A. Martinez-Lemus, M. W. Miller, J. S. Jeffrey, and T. W. Odom, "Echocardiographic evaluation of cardiac structure and function in Broiler and leghorn chickens," Poultry Science, vol. 77, no. 7, pp. 1045-1050, 1998.

[24] C. P. Nautrup and R. Tobias, Diagnostic Ultrasonography of the Dog and Cat, Manson, London, UK, 2000.

[25] M. Nyland and F. Matton, Small Animal Diagnostic Ultrasound, WB Saunders, Philadelphia, Pa, USA, 2002.

[26] J. S. Kim, E. Kuk, K. N. Yu et al., "Antimicrobial effects of silver nanoparticles," Nanomedicine, vol. 3, no. 1, pp. 95-101, 2007. 
[27] M. Singh, S. Singh, S. Prasad, and S. Gambhir, "Nanotechnology in medicine and antibacterial effect of silver nanoparticles," Digest Journal in Nanomaterials and Biostructures, vol. 3, pp. 115-122, 2008.

[28] K.-Y. Yoon, J. Hoon Byeon, J.-H. Park, and J. Hwang, "Susceptibility constants of Escherichia coli and Bacillus subtilis to silver and copper nanoparticles," Science of the Total Environment, vol. 373, no. 2-3, pp. 572-575, 2007.

[29] M. Mühling, A. Bradford, J. W. Readman, P. J. Somerfield, and R. D. Handy, "An investigation into the effects of silver nanoparticles on antibiotic resistance of naturally occurring bacteria in an estuarine sediment," Marine Environmental Research, vol. 68, no. 5, pp. 278-283, 2009.

[30] H. Ahari, F. Dastmalchi, Y. Ghezelloo, R. Paykan, M. Fotovat, and J. Rahmannya, "The application of silver nano-particles to the reduction of bacterial contamination in poultry and animal production," Food Manufacturing Efficiency, vol. 2, pp. 49-53, 2008.

[31] O. Choi, K. K. Deng, N.-J. Kim, L. Ross Jr., R. Y. Surampalli, and $\mathrm{Z}$. Hu, "The inhibitory effects of silver nanoparticles, silver ions, and silver chloride colloids on microbial growth," Water Research, vol. 42, no. 12, pp. 3066-3074, 2008.

[32] J. H. Sung, J. H. Ji, J. D. Park et al., "Subchronic inhalation toxicity of silver nanoparticles," Toxicological Sciences, vol. 108, no. 2, pp. 452-461, 2009.

[33] F. T. W. Jordan and M. Pattison, Poultry Diseases, Elsevier Health Sciences, Amsterdam, The Netherlands, 4th edition, 2001.

[34] L. Akradi, I. Sohrabi Haghdoost, A. N. Djeddi, and P. Mortazavi, "Histopathologic and apoptotic effect of nanosilver in liver of broiler chickens," African Journal of Biotechnology, vol. 11, pp. 6207-6211, 2012.

[35] S. W. P. Wijnhoven, W. J. G. M. Peijnenburg, C. A. Herberts et al., "Nano-silver-a review of available data and knowledge gaps in human and environmental risk assessment," Nanotoxicology, vol. 3, no. 2, pp. 109-138, 2009.

[36] F. Ahmadi and A. Hafsy Kordestany, "Investigation on silver retention in different organs and oxidative stress enzymes in male broiler fed diet supplemented with powder of nano silver," American-Eurasian Journal of Toxicological Sciences, vol. 3, no. 1, pp. 28-35, 2011.

[37] J. F. van Vleet and V. J. Ferrans, "Etiologic factors and pathologic alterations in selenium-vitamin E deficiency and excess in animals and humans," Biological Trace Element Research, vol. 33, no. 1, pp. 1-21, 1992.

[38] N. L. Stedman and T. P. Brown, "Cardiomyopathy in broiler chickens congenitally infected with avian leukosis virus subgroup," Veterinary Pathology, vol. 39, no. 1, pp. 161-164, 2002.

[39] G. Deng, Y. Zhang, X. Peng, D. Guo, and C. Li, "Echocardiographic characteristics of chickens with ascites syndrome," British Poultry Science, vol. 47, no. 6, pp. 756-762, 2006.

[40] L. A. Martinez-Lemus, M. W. Miller, J. S. Jeffrey, and T. W. Odom, "Echocardiographic study of pulmonary hypertension syndrome in broiler chickens," Avian Diseases, vol. 44, no. 1, pp. 74-84, 2000.

[41] M. Pees, J. Straub, and M. E. Krautwald-Junghanns, "Pericardial effusion in birds. Demonstration of clinical cases," in Proceedings of the Association of Avian Veterinarians Annual Conference, pp. 189-191, 2000. 

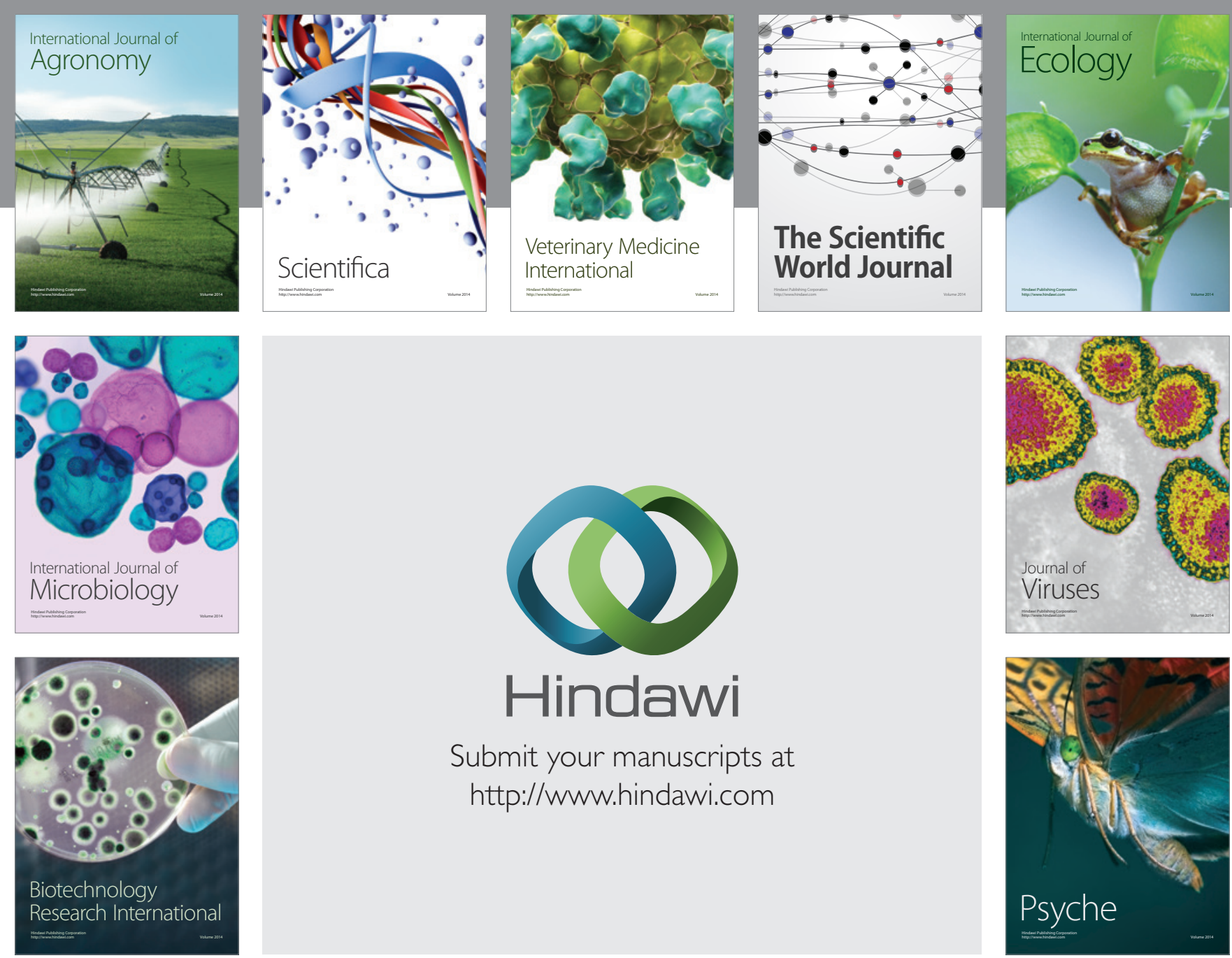

Submit your manuscripts at http://www.hindawi.com
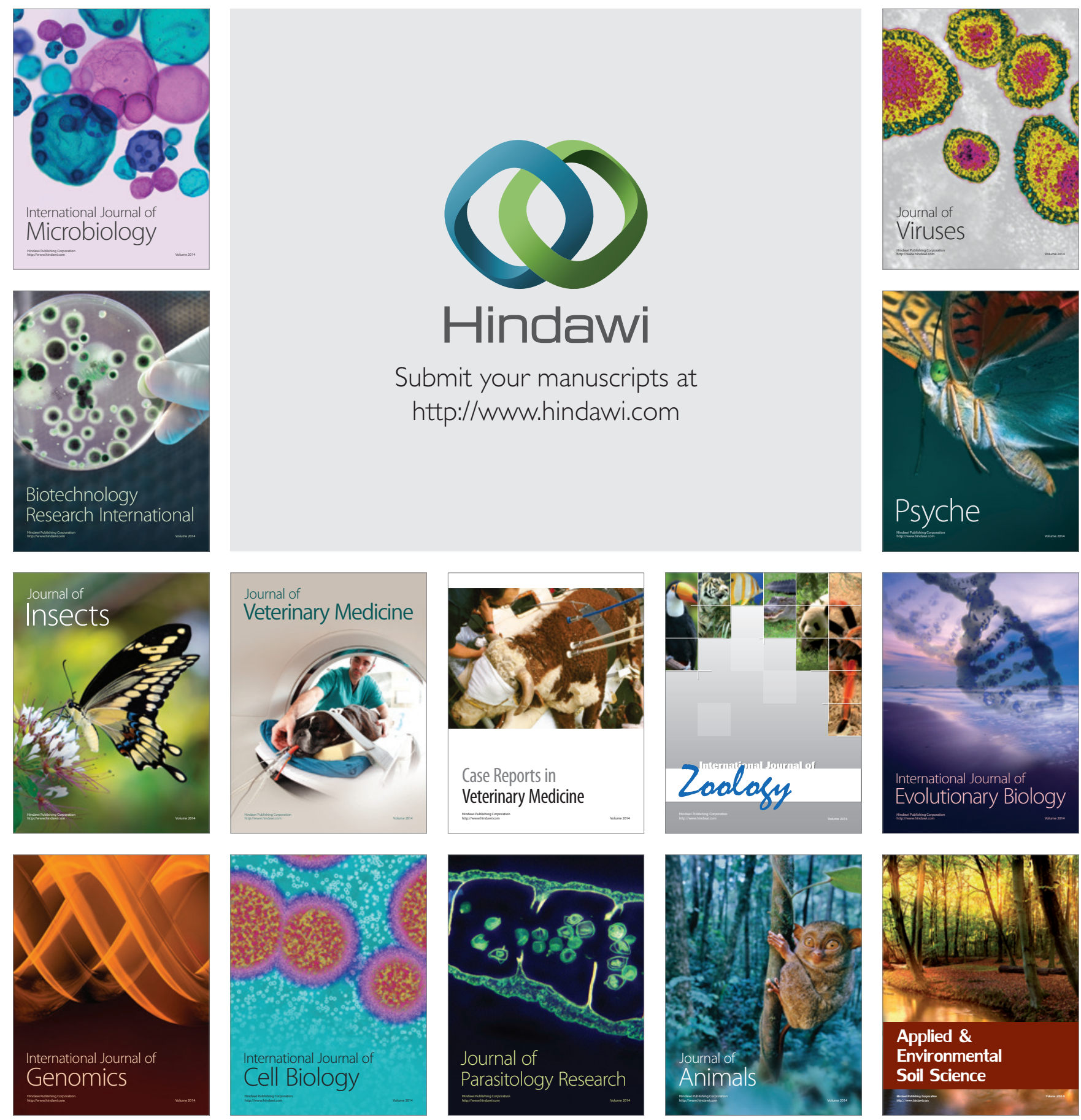